\title{
INFLUÊNCIA DO INTERVALO ENTRE A COLHEITA E A APLICAÇÃO DO 1-METILCICLOPROPENO NO CONTROLE DO AMADURECIMENTO DE MAMÃO ${ }^{1}$
}

\author{
ANGELO PEDRO JACOMINO2, MARCOS JOSÉ TREVISAN ${ }^{3}$, \\ MARIA CECÍLIA DE ARRUDA ${ }^{4}$, RICARDO ALFREDO KLUGE
}

RESUMO - Este trabalho teve como objetivo determinar a influência do intervalo entre a colheita e a aplicação do 1-MCP na sua eficiência como retardador do amadurecimento de mamões 'Golden'. Os frutos foram colhidos em pomares comerciais da região de Linhares-ES, no estádio 2 de maturação, armazenados a $11 \pm 1^{\circ} \mathrm{C}$ e submetidos à aplicação de 1-MCP $\left(100 \mathrm{~nL} . \mathrm{L}^{-1}\right)$ após $0 ; 1 ; 2$ e 3 dias da colheita. Frutos tratados e não-tratados permaneceram durante 6 dias a $11 \pm 1^{\circ} \mathrm{C}$ e, em seguida, foram armazenados a $22 \pm 1,5^{\circ} \mathrm{C}$ e 80 $90 \% \mathrm{UR}$, até completo amadurecimento. O 1-MCP retardou a perda de firmeza e a mudança da cor da casca dos frutos. Os frutos sem 1-MCP atingiram firmeza ideal para consumo entre o $2^{\circ}$ e o $4^{\circ}$ dia a $22^{\circ} \mathrm{C}$. Os frutos que receberam 1-MCP no $2^{\circ}$ ou no $3^{\circ}$ dia após a colheita, atingiram ponto de consumo entre o $8^{\circ}$ e o $10^{\circ}$ dia a $22^{\circ} \mathrm{C}$. Aqueles tratados no $1^{\circ}$ dia após a colheita atingiram firmeza de consumo no $12^{\circ}$ dia a $22^{\circ} \mathrm{C}$, e aqueles que receberam 1-MCP no dia da colheita, não amoleceram. A coloração da casca teve comportamento similar ao da firmeza, porém em menor intensidade. Houve pequeno aumento no teor de sólidos solúveis dos frutos em função do amadurecimento. Quanto menor o intervalo entre a colheita e a aplicação do 1-MCP maior sua eficiência como retardador do amadurecimento de mamões 'Golden'. Essa informação é fundamental na definição da tecnologia de aplicação desse regulador vegetal.

Termos para indexação: Carica papaya, 1-MCP, etileno, firmeza, pós-colheita

\section{INFLUENCE OF THE INTERVAL BETWEEN HARVEST AND 1- METHYLCYCLOPROPENE APPLICATION ON PAPAYA RIPENING}

ABSTRACT - The purpose of this work was to determine the influence of the interval between harvest and 1-MCP application on 1MCP efficiency in delaying ripening in Golden papaya. Fruits were harvested from commercial orchards located in Linhares, ES, in a second stage of maturation, stored at $11 \pm 1^{\circ} \mathrm{C}$ and treated with 1-MCP $\left(100 \mathrm{~nL} \cdot \mathrm{L}^{-1}\right) 0,1,2$ and 3 days after harvest. Treated and nontreated fruits were kept at $11 \pm 1^{\circ} \mathrm{C}$ for 6 days and, then, were stored at $22 \pm 1.5^{\circ} \mathrm{C}$ and $80-90 \% \mathrm{RH}$ until complete ripening. 1-MCP delayed loss of firmness and skin color changes. Non-treated fruits reached ideal firmness for consumption between the $2^{\text {nd }}$ and $4^{\text {th }}$ day of storage at $22^{\circ} \mathrm{C}$. Fruits treated with 1-MCP on the $2^{\text {nd }}$ or $3^{\text {rd }}$ day after harvest reached consumption stage between the $8^{\text {th }}$ and $10^{\text {th }}$ day of storage at $22^{\circ} \mathrm{C}$. While fruits treated with $1-\mathrm{MCP}$ one day after harvest reached optimum firmness for consumption on the $12^{\text {th }}$ day of storage at $22^{\circ} \mathrm{C}$, those treated on the harvest day did not softened. Though more subtly, skin color behaved in a similar way as firmness. There was a slight increase in soluble solids amounts in fruits along ripening. The lower the interval between harvest and 1MCP application, the longer the 1-MCP efficiency in delaying ripening in Golden papaya. This is the key information when defining the application procedure for $1-\mathrm{MCP}$ as a ripening regulator.

\section{INTRODUÇÃO}

O Brasil é o maior produtor mundial de mamão, sendo responsável por aproximadamente $25 \%$ do total produzido (FNP, 2005). O mamão é um fruto climatérico que apresenta curto período de vida útil após a colheita, como conseqüência do rápido amadurecimento e senescência (Paull, 1993).

O etileno está envolvido na aceleração do amadurecimento e da senescência de frutos climatéricos. Em determinado estádio da maturação, o etileno liga-se ao seu receptor na célula, um complexo protéico-enzimático, e desencadeia uma série de eventos que culminam com o amadurecimento e a senescência do fruto (Burg \& Burg, 1967;
Lelievre et al., 1997).

O uso de técnicas que retardem os processos fisiológicos é bastante desejável. Uma das formas consiste em inibir a ação do etileno. O 1-MCP tem-se mostrado bastante eficiente em reduzir a produção e bloquear a ação do etileno em diversas espécies de flores, frutos e hortaliças. Esse composto liga-se permanentemente ao sítio de ligação do etileno na célula, evitando, por certo tempo, a ação do mesmo sobre processos fisiológicos do amadurecimento. A sensibilidade do tecido vegetal ao etileno, com conseqüente amadurecimento do fruto, retorna devido à síntese de novos sítios de ligação (Blankenship \& Dole, 2003).

A aplicação do 1-MCP em mamão 'Sunrise Solo'

'(Trabalho 173-06). Recebido em:30-10-2006. Aceito para publicação em: 22-06-2007

2Engenheiro agrônomo, Doutor em Agronomia, Professor da ESALQ/USP, Av. Pádua Dias, 11, C.P 09 - Piracicaba-SP, jacomino@esalq.usp.br;

${ }^{3}$ Engenheiro agrônomo, Mestre em Agronomia, ESALQ/USP, mjtrevis@esalq.usp.br;

${ }^{4}$ Engenheira agrônoma, Doutora em Agronomia, Pesquisadora da APTA Regional Centro Oeste, Av. Rodrigues Alves, 40-40, 17030-000, Bauru-SP, mcarruda@aptaregional.sp.gov.br;

${ }^{5}$ Engenheiro agrônomo, Doutor em Agronomia, Professor da ESALQ/USP, rakluge@esalq.usp.br. 
proporcionou o aumento do período de conservação em até três dias (Jacomino et al., 2002). Há uma série de fatores que devem ser considerados na utilização da tecnologia do 1-MCP, como: cultivar, estádio de desenvolvimento do fruto, intervalo entre a colheita e o tratamento, múltiplas aplicações, entre outros (Blankenship \& Dole, 2003).

A tecnologia de uso desse regulador já está ajustada para algumas espécies e ainda em desenvolvimento para outras, como é o caso do mamão. Conhecer a influência do intervalo entre a colheita e a aplicação do 1-MCP, na resposta do fruto, é de grande importância para a definição da tecnologia de aplicação comercial desse regulador vegetal. Assim, o objetivo deste trabalho foi determinar a influência do intervalo entre a colheita e o tratamento com 1-MCP na conservação de mamões 'Golden'.

\section{MATERIAL E MÉTODOS}

Mamões da variedade 'Golden' foram colhidos em pomares comerciais no município de Linhares-ES, e levados imediatamente para a casa de embalagem, onde foram beneficiados, selecionados e armazenados a $11^{\circ} \mathrm{C}$. Foram selecionados apenas frutos no estádio 2 de maturação (máximo $16-25 \%$ da casca amarela). Os frutos receberam aplicação de 1MCP na concentração de 100 nL.L-1 após $0 ; 1 ; 2$ ou 3 dias da colheita. A aplicação constou da colocação de aproximadamente 120 frutos em caixas plásticas que permitem fechamento hermético com capacidade de $186 \mathrm{~L}$ e exposição ao produto por 12 horas, sob refrigeração. Para gerar a concentração desejada de 1-MCP, utilizou-se SmartFresh na formulação pó-molhável $0,14 \%$ de i.a. Frutos sem aplicação de 1-MCP foram utilizados como controle. Ao final de 12 horas de tratamento, coletaramse amostras de ar do interior das caixas para a determinação do teor de etileno.

Imediatamente antes de cada tratamento, os frutos foram caracterizados quanto à firmeza da polpa e ao teor de sólidos solúveis.

Decorridos 6 dias da colheita, os frutos de todos os tratamentos foram transportados em caminhão refrigerado para o Laboratório de Pós-Colheita do Depto. de Produção Vegetal da ESALQ/USP, em Piracicaba-SP, e mantidos a $22 \pm 1,5^{\circ} \mathrm{C}$ e $80-90 \%$ UR, até o completo amadurecimento. Os frutos foram considerados maduros com firmeza da polpa entre 20 e $7 \mathrm{~N}$ e sobremaduros com firmeza menor que $7 \mathrm{~N}$. Os frutos foram analisados a cada dois dias quanto a cor da casca e firmeza da polpa e, quando atingiram o ponto de consumo, foram analisados também quanto ao teor de sólidos solúveis. Os frutos foram considerados em ponto de consumo quando atingiram a firmeza da polpa de 20N, de acordo com Bron \& Jacomino (2006).

O delineamento experimental foi inteiramente ao acaso, com 15 repetições de um fruto por tratamento, em cada dia de avaliação.

A metodologia de análise utilizada foi a seguinte: a) cor da casca: determinada com colorímetro Minolta CR-300, tomando-se quatro leituras em lados opostos do fruto, na região de maior diâmetro. Os resultados foram expressos em $\mathrm{h}^{\circ}$ (ângulo de cor hue), considerando a média de quatro leituras. $\mathrm{O} \mathrm{h}^{\circ}$ define a coloração básica, onde $0^{\circ}=$ vermelho; $90^{\circ}=$ amarelo, e $180^{\circ}=$ verde (McGuirre, 1992); b) firmeza da polpa: determinada com penetrômetro digital equipado com ponteira de $8 \mathrm{~mm}$, tomandose quatro leituras em lados opostos do fruto, na região de maior diâmetro, após a retirada da epiderme. Os resultados foram expressos em Newtons $(\mathrm{N})$, considerando a média de quatro leituras; c) teor de sólidos solúveis: determinado em refratômetro digital, utilizando uma porção de polpa da região equatorial de cada fruto. Os resultados foram expressos em ${ }^{\circ}$ Brix; d) teor de etileno no interior das câmaras de tratamento: para a coleta de amostras de ar, foram utilizadas bombas de sucção que foram conectadas hermeticamente às câmaras de tratamento e a bolsas especiais "sample bags". A determinação do teor de etileno foi realizada em cromatógrafo a gás, marca Thermoffinigan, modelo Trace 2000, equipado com detector de ionização de chama (FID), injetor e coluna Porapack N de 1,8 metros.

Os resultados foram submetidos à análise de variância, à comparação de médias pelo teste de Tukey (5\%) e à análise do erro-padrão.

\section{RESULTADOS E DISCUSSÃO}

Houve redução da firmeza da polpa dos mamões, após a colheita, mesmo sob refrigeração (Tabela 1 ). No $3^{\circ}$ dia após a colheita, a firmeza da polpa foi aproximadamente $25 \%$ menor que no dia da colheita.

Os frutos que receberam 1-MCP perderam a firmeza mais lentamente do que os frutos sem 1-MCP, e quanto menor o intervalo entre a colheita e o tratamento, maior foi o efeito deste regulador vegetal (Figura 1).

Os frutos sem 1-MCP atingiram firmeza de consumo $(20 \mathrm{~N})$ entre o $2^{\circ}$ e o $4^{\circ}$ dia de amadurecimento a $22^{\circ} \mathrm{C}$. Os frutos que receberam 1-MCP após 2 ou 3 dias de colhidos, atingiram condição de consumo entre o $8^{\circ}$ e o $10^{\circ}$ dia de amadurecimento. Aqueles tratados com 1 dia após a colheita, somente atingiram firmeza de consumo no $12^{\circ}$ dia de amadurecimento. Já, os frutos que receberam 1-MCP no dia da colheita, não amoleceram até o $12^{\circ}$ dia em condição ambiente, embora a casca tenha-se tornado de cor amarela a alaranjada, semelhante ao controle.

A retenção da firmeza em resposta ao tratamento com 1MCP também foi verificada por Jacomino et al. (2002) e por Ergun \& Huber (2004), em dois estádios de maturação de mamões 'Sunrise Solo'. Hofman et al. (2001) observaram que os frutos cultivar 'Solo', tratados com $25 \mu \mathrm{L}^{-1}$ de 1-MCP e armazenados a $20^{\circ} \mathrm{C}$, amadureceram após, aproximadamente, 20 dias. A perda da firmeza está relacionada ao etileno, que ativa enzimas pectnolíticas, que transformam a pectina insolúvel em solúvel (Leliévre et al., 1997).

Os frutos que receberam 1-MCP no dia da colheita, provavelmente, perderam a capacidade de sintetizar novos sítios de ligação do etileno, e/ou a produção de etileno por estes frutos foi insuficiente para desencadear a ativação de enzimas relacionadas à mudança de textura. De modo geral, os frutos apresentavam-se com boa aparência até o $8^{\circ}$ ou, no máximo, até o $10^{\circ}$ dia a $22^{\circ} \mathrm{C}$.

Embora a coloração da casca tenha sido menos 
influenciada pelos tratamentos que a firmeza da polpa, verificouse comportamento similar para ambas as variáveis. De forma geral, observou-se que, quanto menor o intervalo entre a colheita e a aplicação do 1-MCP, maior o tempo para o amarelecimento dos frutos (Figura 2).

$\mathrm{O}$ amarelecimento é decorrente da quebra da estrutura da molécula de clorofila pela atividade da enzima clorofilase. $\mathrm{O}$ aumento da atividade desta enzima está geralmente associado com a produção de etileno durante o amadurecimento do fruto (Tucker, 1993).

Os frutos tratados no dia da colheita apresentaram menor produção de etileno (Figura 3), o que provavelmente contribuiu para a ação mais intensa do 1-MCP nesses frutos. Observa-se que houve aumento na produção de etileno à medida que os frutos ficaram armazenados a $11^{\circ} \mathrm{C}$, em função do próprio processo de amadurecimento, que resultou também em perda de firmeza, conforme observado na Tabela 1. Isto explica a maior resposta dos frutos ao 1-MCP quando a aplicação ocorreu no dia da colheita. Os frutos que receberam 1-MCP neste dia, apresentaram baixa produção de etileno e firmeza da polpa elevada, resultado da acentuada ação do 1-MCP. Por outro lado, os frutos que receberam 1-MCP após um dia ou mais de armazenamento, apresentaram produção de etileno muitas vezes maior, e, provavelmente, os diversos processos de amadurecimento já tinham sido desencadeados pela ação do etileno.

Mamões 'Golden' colhidos no estádio 2 de maturação continuaram o processo de amadurecimento mesmo quando conservados sob refrigeração. Isto ficou bem demonstrado pelos valores de firmeza da polpa nos primeiros três dias após a colheita e pelos valores de etileno nos primeiros dois dias de armazenamento após a colheita. Esses poucos dias de armazenamento resultam em grande alteração na sensibilidade dos frutos ao inibidor da ação do etileno, 1-MCP. Essa informação é de grande importância para a definição da tecnologia de uso comercial do 1-MCP, onde esse intervalo pode ser usado como ferramenta para maximizar ou reduzir os efeitos do regulador. São necessários maiores estudos com o 1-MCP em mamão, de forma que se alcance o aumento no tempo de conservação sem prejuízo do amadurecimento.

Quanto menor o intervalo entre a colheita e o tratamento, menor a concentração de etileno detectada no interior das câmaras. Isto explica a ação mais intensa do 1-MCP aplicado no dia da colheita, em comparação à aplicação alguns dias após a colheita. Fan et al. (2000) também observaram que o efeito do 1MCP em damasco decresceu com o avanço da maturidade do fruto. No entanto, Dong et al. (2002) observaram menor produção de etileno em frutos de ameixa e damasco, quando estes foram tratados após o armazenamento (estádio de maturação mais avançado).

O teor de sólidos solúveis dos frutos não foi afetado pelo tratamento com 1-MCP (dados não apresentados). Resultados semelhantes também foram observados em laranja (Porat et al., 1999), em ameixa e damasco (Dong et al., 2002), em manga (Hofman et al., 2001) e em maçã (Rupasinghe et al. 2000; DeEll et al., 2002). Em mamão, Hofman et al. (2001) observaram maior teor de sólidos solúveis em frutos tratados com 1-MCP. Apesar de o mamão apresentar baixo teor de amido (menos do que 1\%) para ser hidrolisado, observou-se aumento no teor de sólidos solúveis dos frutos em função do amadurecimento (Pd"0.05).

Os frutos foram colhidos com teor de sólidos solúveis de $8,8^{\circ}$ Brix e, após o amadurecimento, atingiram valores entre 9,92 e $10,21^{\circ}$ Brix

TABELA 1 - Firmeza da polpa de mamões 'Golden' colhidos no estádio 2 de maturação e armazenados a $11^{\circ} \mathrm{C}$.

\begin{tabular}{cc}
\hline Dias após a colheita & Firmeza (N) \\
\hline 0 & 120,92 \\
1 & 110,88 \\
2 & 109,29 \\
3 & 93,55 \\
\hline
\end{tabular}

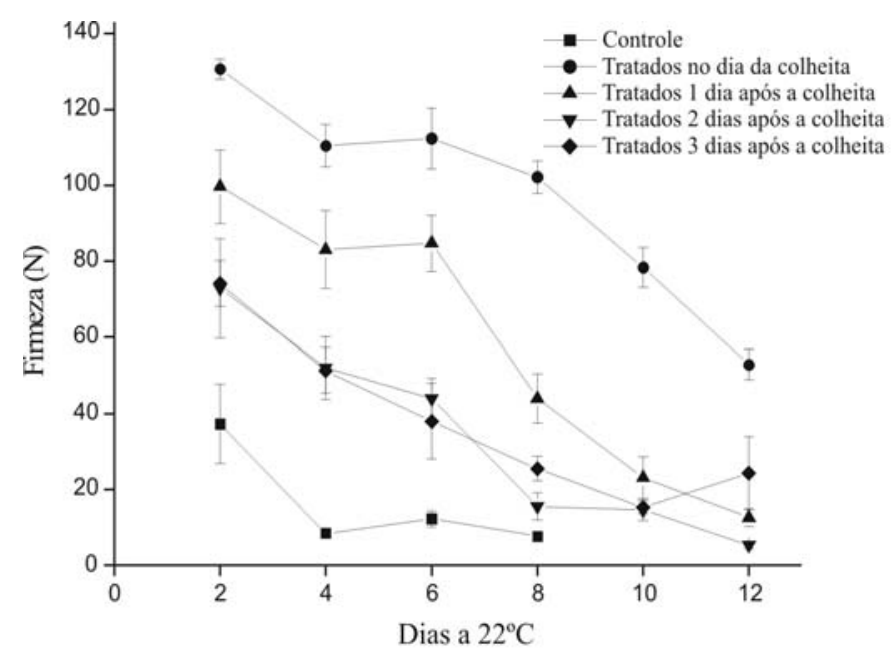

FIGURA 1 - Influência do 1-MCP na firmeza da polpa de mamões 'Golden' em função do intervalo entre a colheita e o tratamento.

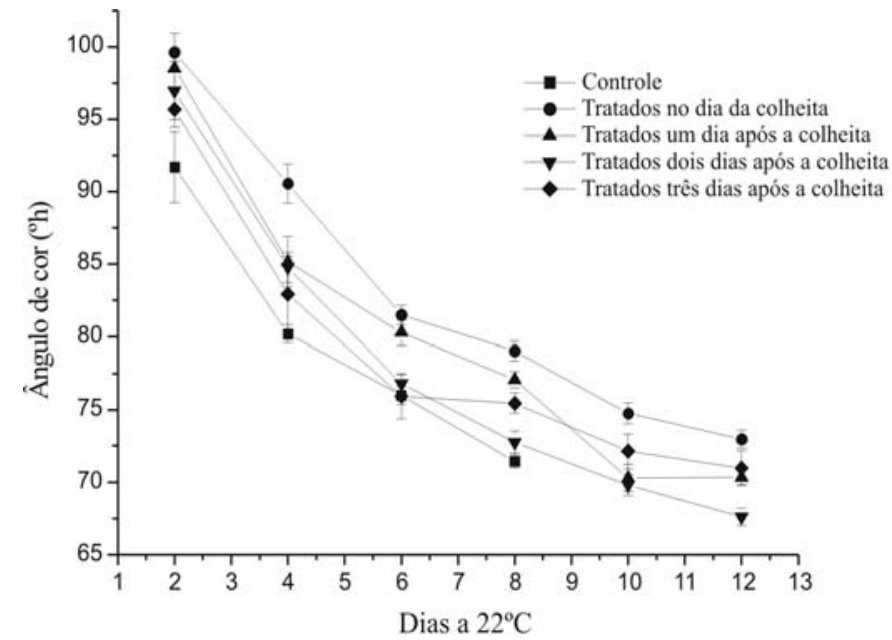

FIGURA 2 - Influência do 1-MCP na cor da casca de mamões 'Golden' em função do intervalo entre a colheita e o tratamento. 


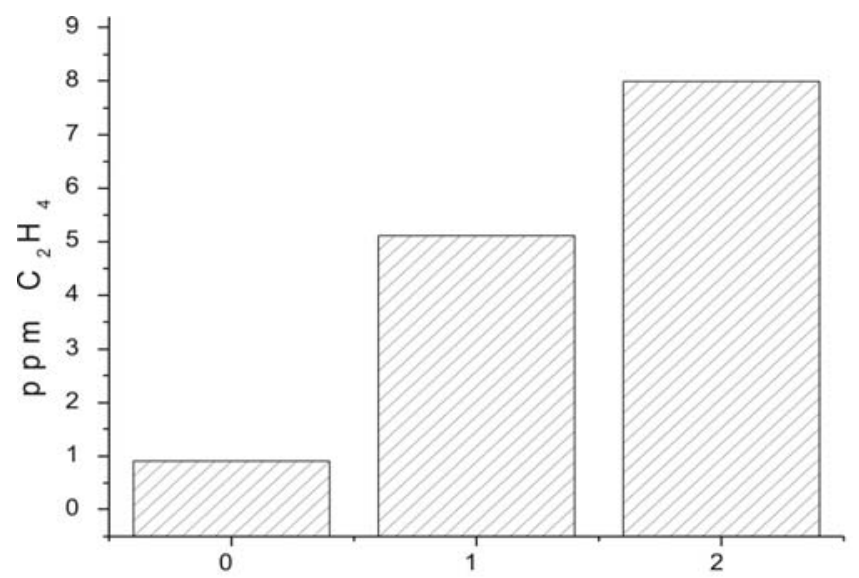

FIGURA 3 - Concentração de etileno no interior das caixas plásticas após $12 \mathrm{~h}$ de tratamento com 1-MCP. Frutos recém-colhidos (0); um dia após a colheita (1); dois dias após a colheita (2).

\section{AGRADECIMENTOS}

À Caliman Agrícola S.A. e à AgroFresh Inc.

\section{CONCLUSÃO}

Quanto menor o intervalo entre a colheita e a aplicação do 1-MCP, maior seu efeito como retardador do amadurecimento de mamões 'Golden'.

\section{REFERÊNCIAS}

AGRIANUAL 2005: anuário da agricultura brasileira. Mamão. São Paulo: FNP CONSULTORIA \& COMÉRCIO, 2005. p.371379:

BLANKENSHIP, S.M.; DOLE, J.M. 1-Methylcyclopropene: a review. Postharvest Biology and Technology, Amsterdam, v.28, p.1-25, 2003.

BRON, I.U.; JACOMINO, A.P. Ripening and quality of 'Golden' papaya fruit harvested at different maturity stages. Brazilian Journal Plant Physiology, Londrina, v.18, n.3, p.389-396, 2006.

BURG, S.P.; BURG, E.A. Molecular requeriments for the biological activity of ethylene. Plant Physiology, Rockville, v.42, p.144-152, 1967.

DeELL, J.R.; MURR, D.P.; PORTEOUS, M.D.; RUSPASINGHE, H.P.V. Influence of temperature and duration of 1-methylcyclopropene (1-MCP) treatment on apple quality. Postharvest Biology and Technology, Amsterdam, v.24, p.349353, 2002.
DONG, L.; LURIE, S.; ZHOU, H.W. Effect of 1methylcyclopropene on ripening of 'Canino' apricots and 'Royal Zee' plums. Postharvest Biology and Technology, Amsterdam, v.24, n.2, p.135-145, 2002.

ERGUN, M.; HUBER, D.J. Suppression of ethylene perception extends shelf-life and quality of 'Sunrise Solo'papaya fruit at both pre-ripe and ripe stages of development. European Journal of Horticultural Science, Hannover, v.69, n.5, p.184-192,2004.

FAN, X.; ARGENTA, L.; MATTHEIS, J.P. Inhibition of ethylene action by 1-methylciclopropene prolongs storage life of apricots. Postharvest Biology and Technology, Amsterdam, v.20, p.135$142,2000$.

HOFMAN, P.J.; JOBIN-DÉCOR, M.; MEILBURG, G.F.; MACNISH, A.J.;JOYCE, D.C. Ripening and quality responses of avocado, custard apple, mango and papaya fruit to 1methylcyclopropene. Australian Journal of Experimental Agriculture, Victoria, v.41, p.567-572, 2001.

JACOMINO, A.P.; KLUGE, R.A.; BRACKMANN, A.; CASTRO, P.R.C. Amadurecimento e senescência de mamão com 1-metilciclopropeno. Scientia Agrícola, Piracicaba, v.59, n.2, p.303-308, 2002.

LELIEVRE, J.M.; TICHIT, L.; DAO, P.; FILLION, L.; NAM, Y.W.; PECH, J.C.; LATCHÉ, A. Effects of chilling on the expression of ethylene biosynthetic genes in Passe-Crassane pear (Pyrus communis L.) fruits. Plant Molecular Biology, Dordrecht, v.33, p.847-855, 1997.

McGUIRRE, R.G. Reporting of objective color measurents. HortScience, Alexandria, v.27, n.12, p.1254-1255, 1992.

PAULL, R.E. Pineapple and papaya. In: SEYMOUR, G.B.; TAYLOR, J.E.; TUCKER, G.A. (Ed.) Biochemistry of fruit ripening. London: Chapman \& Hall, 1993.p.291-323.

PORAT, R.; WEISS, B.; COHEN, L.; DAUS, A.; GOREN, R.; DROBY, S. Effects of ethylene and 1-methylcyclopropene on the postharvest qualities of 'Shamouti' oranges. Postharvest Biology and Technology, Amsterdam, v.15, p.155-163, 1999.

RUPASINGHE, H.P.V.; MURR, D.P; PALIYATH, G.; SKOG, L. Inhibitory effect of 1-MCP on ripening and superficial scald development in 'McIntosh' and 'Delicious' apples. Journal of Horticultural Science Biotechnology, Kent, v.75, p.271-276, 2000.

TUCKER, G.A. Introduction. In: SEYMOUR, G.B.; TAYLOR, J.E.; TUCKER, G.A. (Ed.) Biochemistry of fruit ripening. London: Chapman \& Hall, 1993.p.1-51. 